Evans, R. J. \& Brant, A. W. (1945). Poult. Sci. 24, 404.

Ewing, W. R. (1947). Poultry Nutrition, 3rd ed. (revised). South Pasadena, California: W. Ray Ewing.

Glazener, E. W. \& Briggs, G. M. (1948). Poult. Sci. 27, 462.

Glazener, E. W., Mattingly, J. P. \& Briggs, G. M. (1946). Poult. Sci. 25, 85.

Hammond, J. C. (194I). Poult. Sci. 20, 369.

Harris, L. J. (1948-9). Brit. F. Nutrit. 2, 362.

Hart, E. B., Halpin, J. G. \& Steenbock, H. (1920). F. biol. Chem. 43, 42 I.

Hart, E. B., Halpin, J. G. \& Steenbock, H. (1922). \%. biol. Chem. 52, 379.

Hart, E. B., Steenbock, H., Lepkovsky, S. \& Halpin, J. G. (1923). F. biol. Chem. 58, 33.

Hart, E. B., Steenbock, H., Lepkovsky, S. \& Halpin, J. G. (r924). J. biol. Chem. 60, 341.

Hou, H.-C. (1928). Chin. F. Physiol. 2, 345.

Hou, H.-C. (1931). Chin. F. Physiol. \$, I1.

Kline, O. L., Bird, H. R., Elvehjem, C. A. \& Hart, E. B. (1936). F. Nutrit. Ir, 515.

Knowles, H. R., Hart, E. B. \& Halpin, J. G. (1935). Poult. Sci. I4, 33.

Koch, E. M. \& Koch, F. C. (1941). Poult. Sci. 20, 33.

Kuhn, R. \& Grundmann, C. (1934). Ber. desch. chem. Ges. 67, 593.

McGinnis, J., Kosin, I. L. \& Decker, A. (1947). Poult. Sci. 26, 550.

Meunier, P. (1948-9). Brit. F. Nutrit. 2, 396.

Moore, T. (1 948-9). Brit. F. Nutrit. 2, 407.

Motzok, I., Graham, W. D., Branion, H. D. \& Slinger, S. J. (1946). Poult. Sci. $25,298$.

Mussehl, F. E. \& Ackerson, C. W. (1930). Poult. Sci. 9, 334.

Mussehl, F. E. \& Ackerson, C. W. (1935). Poult. Sci. 14, 147.

Nowotarski, J. S. \& Bird, H. R. (1943). Poult. Sci. 22, 72.

Olsson, N. (1942). LantbrHogsk. Husdjursforsoksanst. Medd. no. I4.

Pappenheimer, Goettsch \& Jungherr (1939). Bull. Storrs agric. Exp. Sta. no. 229.

Patrick, H. \& Morgan, C. L. (1944). Poult. Sci. 23, 525.

Sugiura, K. \& Benedict, S. R. (1923). F. biol. Chem. 55, 33.

Waddell, J. (1934). Y. biol. Chem. ro5, 7 I 1.

Waddell, J. \& Steenbock, H. (1928). F. biol. Chem. 80, 43 I.

\title{
The Incidence of Nutritional Diseases in Poultry
}

\section{By J. E. WiLson, Ministry of Agriculture and Fisheries, Poultry Laboratory, Eskgrove, Lesswade, Midlothian}

It is not possible in a short space to cover the whole field of diseases of poultry associated with faulty diet; the subject may, however, be discussed briefly under three headings: ( 1 ) diseases associated with a specific deficiency; (2) diseases due to nonspecific deficiency; (3) diseases possibly associated with faulty diet.

The importance of an adequate diet for the maintenance of poultry in normal health and for the efficient production, fertility and hatchability of eggs need not be stressed, as it is well recognized. Formerly, when fowls were reared extensively on grass, having access to worms, grubs and insects, coming into contact with their own droppings and being exposed to sunlight, there was little likelihood of diseases due to deficiency in the diet. With the increased use of the intensive system and more particularly of the battery system, fowls depend solely on the ingredients in their mash, and deficiency diseases have become more common.

Some conception of the prevalence of these diseases may be obtained from a survey of the results of post-mortem examinations of chicks and fowls from stations participating in the Accredited Poultry Schemes in Scotland and in the six northern counties of England during the period r940-8. The results are given in Table I. Comparable figures for the industry as a whole are higher, since the regulations of these schemes 
demand a certain standard of health, hygiene and husbandry; some degree of supervision and inspection is imposed, and help and advice are available from the County Poultry Instructresses and from members of the veterinary staff of the Animal Health Division of the Ministry of Agriculture.

Table I. Summary of disease outbreaks among chicks and fowls from stations participating in the Accredited Poultry Schemes in Scotland and in the six northern counties of England, 1940-8

Total no. of outbreaks: Adults 7317

Chicks 9627

$\begin{array}{lrlr}\text { Tuberculosis } & 259 & \text { Coccidiosis } & 876 \\ \text { Fowl paralysis } & 574 & \text { Bacillary white diarrhoea } & 195 \\ \text { Leukaemia } & 455 & \text { Salmonellosis } & 90 \\ \text { Nephritis } & 1060 & \text { Deficiency diseases } & 136 \\ \text { Aspergillosis } & 104 & & \end{array}$

In almost all the outbreaks investigated, specific and advanced symptoms and lesions associated with a serious deficiency were present. Sometimes, however, the deficiency may be only partial, and the non-specific symptoms of retarded and uneven growth and lowered egg production may not be spectacular or serious enough to compel the seeking of advice. The figure of $\mathrm{I}_{3} 6$, quoted in Table $\mathrm{I}$, must, therefore, be regarded as a minimum, and an indication, rather than an accurate estimate, of the position.

An examination of the outbreaks shows that the conditions met with are, in descending order of incidence, rickets, in both chicks and adult stock, curled-toe paralysis and other manifestations of a deficiency of the vitamin B complex, perosis, vitamin A deficiency and encephalomalacia (vitamin E deficiency) (Table 2).

Table 2. Number of outbreaks of deficiency diseases among chicks and fowls from stations participating in the Accredited Poultry Schemes in Scotland and in the six northern counties of England, 1940-8

$\overbrace{\begin{array}{c}\text { Chicks } \\ 64\end{array} \quad \begin{array}{c}\text { Adults } \\ 18\end{array}}^{\text {Rickets }}$

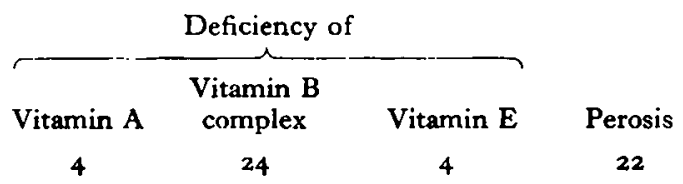

\section{Rickets}

\section{Diseases associated with a specific deficiency}

This is the commonest deficiency disease in chicks and is characterized by leg weakness, stunted growth, ruffled feathers and general unthriftiness. The bones become soft and bend readily when pressure is applied. The ribs exhibit a wavy appearance and become collapsed. Curvature of the spine sometimes occurs, and the sternum is markedly bent. In advanced cases the toes and beaks become soft and pliable.

In adult birds kept in confinement, particularly in batteries, on a deficient diet, a similar disease develops. Thin-shelled, later soft-shelled, eggs are laid. The bones become soft and prone to fracture, and symptoms develop indistinguishable from those of neurolymphomatosis, for which the condition is sometimes mistaken. In advising, it 
is usual to suggest the addition of cod-liver oil as an immediate measure, and. if this is not followed by early improvement, it should be ascertained whether adequate calcium is available, and in the correct ratio.

\section{Curled-toe paralysis and other manifestations of a deficiency of vitamin $B$ complex}

In the general diagnosis laboratory, as distinct from the specialist nutritional laboratory, it is not always possible to determine which factor in this complex group is responsible for the symptoms observed, but from the purely practical standpoint of control and prevention this is unimportant.

Symptoms may be indefinite and include retarded growth, leg weakness and emaciation, but frequently chicks received for examination show the typical curled-toe paralysis characteristic of riboflavin deficiency. Affected birds sit on their hocks with the toes turned in, and when made to move walk on their hocks, using the wings as supports. In extreme cases birds are unable to move and lie in a sprawling position. In adult birds there is a decrease in egg production, with high embryonic mortality. Affected embryos are oedematous and have defective down as a result of failure of the feathers to rupture the sheaths. In the turkey crusty sores appear at the corners of the mouth and on the eyelids, accompanied in some cases by dermatitis of the feet.

In pantothenic acid deficiency in chicks growth is retarded, feathers are rough and crusty scabs appear at the corners of the mouth. Eyelids are frequently stuck together. Cracks develop in the skin between the toes. Somewhat similar symptoms occur in biotin deficiency. In severe cases the toes may slough, and in addition some affected birds may have perosis. When lesions are confined to the feet the possibility of access to disinfectants, caustic materials or other irritants should always be considered.

Symptoms of folic acid deficiency, characterized by uneven feather growth, may develop in birds fed on a normal diet where prolonged medication with sulphonamides, e.g. in the treatment of coccidiosis, upsets the normal bacterial flora of the intestines. Other vitamin $B$ factors may be similarly affected by this means, and rancidity of the food may sometimes be responsible. The addition of inactivated yeast or dried skim milk is generally effective if the symptoms are not advanced, but under present conditions it is extremely difficult to advise on treatment, owing to the difficulty in obtaining these substances.

\section{Perosis}

This condition, which affects growing chicks and turkeys, is characterized by a deformity of one, or both, limbs associated with swelling of the hock joint, followed by torsion, finally resulting in displacement of the Achilles tendon. It is most often due to a deficiency of manganese, but can also occur in biotin or choline deficiency. The feeding of diets rich in phosphorus aggravates the condition, and many of our cases are associated with the feeding of large amounts of meat-and-bone meal in the ration. An adequate supply of manganese is necessary for adult stock. With defective diets egg production is lowered, shell texture is poor, and a high embryonic mortality occurs during the last stages of incubation. The affected embryos have shortened limbs and the 
lower mandible is undershot, giving rise to the condition commonly termed 'parrot beak'.

Symptoms of manganese deficiency regularly occur in early spring in certain flocks where breeding stock is on poor grass or bare runs, and disappear with the coming of the fresh growth of grass. The shell texture may suggest a lack of calcium to the owner, who gives an additional supply which aggravates the condition. About 4 oz. manganese sulphate per ton of food is adequate as a preventive.

\section{Vitamin $A$ deficiency}

Vitamin A deficiency may be commoner in poultry generally than the survey of our selected population suggests. Symptoms in the adult are a decrease in egg production, ruffled feathers, weakness, emaciation and a watery discharge from eyes and nose somewhat suggestive of contagious catarrh. Later the discharge becomes whitish in colour and caseous in consistency, and a large amount may collect under the eyelids. Small, discrete, whitish yellow pustule-like lesions develop in the pharynx and upper oesophagus. In chicks there is cessation of growth at 3-4 weeks of age, weakness in co-ordination, and emaciation. There may be a lack of yellow pigment in the shanks and beak in breeds where it should normally be present, and there is usually, although not invariably, a watery discharge from the eyes. It is particularly important that breeding stock should have an adequate reserve of vitamin $A$, otherwise chick mortality will be high during the first 2 weeks of life, irrespective of the amount of vitamin $A$ present in their diet.

\section{Vitamin $E$ deficiency-encephalomalacia of chicks}

This condition is not of great importance from a practical standpoint, but as it is of considerable interest a short description is included.

Five natural outbreaks have come to our notice and all have been associated with the feeding of additional cod-liver oil, in some cases in relatively large amounts. It has been shown that the disease is due not to the large amount of oil but to the presence of a substance in certain oils which prevents the utilization of vitamin $E$ in the diet.

The condition usually develops when the chicks are 2-4 weeks old and is characterized by sleepiness and immobility followed by incoordination. The head may be retracted over the back or may be tucked between the legs. Some chicks fall on their sides and lie kicking, and others fall over backwards and exhibit a pedalling action.

Post-mortem examination shows oedema of the meninges, and the cerebellum is swollen, soft and smooth in appearance, with opaque areas. The only treatment we have suggested is to change over to a fresh supply of cod-liver oil and to give it at a normal level.

\section{Six-day chick disease}

\section{Diseases due to a non-specific deficiency}

During the war it was not possible to adhere to formulas shown by experience to be successful for chick rearing, and in 1944 serious losses occurred in chicks during the Ist and and week of life, with symptoms and post-mortem findings indistinguishable 
from those of chilling. The term '6-day chick disease' was coined to describe the condition.

It was thought that an excessively high fibre content of the diet was responsible, but this was certainly not so in every case. Temperton \& Bythell (1944) suggested that it was due to a lack of available energy in the diet, and that it could be overcome by the addition of glucose. The addition of kibbled grain or dried milk also proved effective.

Work which I carried out with Prof. Robertson showed that diets which caused the disease in the field could be used under experimental conditions without reproducing the disease, provided the temperature of the brooders was kept high, and it was shown subsequently that a very high level of fibre could then be given with safety. Outbreaks ceased when maize again became available for incorporation in chick mashes.

\section{Cannibalism}

Cannibalism in chicks and adult fowls may become a serious source of loss if undetected in its initial stages, as the vice spreads rapidly throughout the flock. The region of the vent is a common site of attack, and once the peritoneal cavity is penetrated evisceration rapidly follows; often the entire intestinal tract except for a small portion of duodenum is removed. In the most serious outbreak in our experience more than 500 birds out of a total flock of just over 600 were lost within 3 days.

Environmental conditions, including overcrowding, boredom and parasitism are important predisposing factors, and it would appear from Dr Greenwood's observations (Greenwood \& Blyth, r948) that the genetic constitution is of importance.

The diet is of primary importance in many outbreaks, a deficiency of sodium chloride, manganese or protein being held responsible. In the United States the feeding of excessive amounts of maize has been blamed; this can be disregarded here under present conditions. Kull (1948) obtained good results by the addition of manganese sulphate $(0.02 \mathrm{~g}$./bird/day) and, in some flocks, which did not respond and in which feather eating was a prominent symptom, by the further addition of horn meal $(5-12 \%$ in mash).

\section{Diseases possibly associated with diet}

\section{Pullet disease (blue comb)}

Within recent years nephritis has become an important cause of poultry losses, and it has been suggested that in some cases the diet may be responsible. On some farms the disease is confined to individuals of one breed or even to strains within a breed, so that apparently the genetic constitution is of importance in determining susceptibility. Pullet disease, i.e. the simultaneous appearance of multiple cases of nephritis within a flock, has been known in America for about 20 years, and has recently become prevalent in this country. An extensive bibliography is available, but a definite cause has not yet been found. Almost every outbreak investigated has coincided with the use of a fresh consignment of feeding-stuff, but it has never been possible to reproduce the disease in the laboratory by feeding the same food. New grain, 'heated' pellets, mouldy food or rancid mash have all been suggested as possible causes. Pullets which 
have recently begun to lay are most susceptible, but hens and cockerels are sometimes affected.

The disease is characterized by a sudden drop, sometimes almost a complete cessation, of egg production, accompanied by marked cyanosis of comb and wattles, dullness, loss of appetite, watery diarrhoea. Many birds in the flock (up to $90 \%$ ) may be affected but mortality is usually low (about $2-20 \%$ ). Recovery generally takes place in about 14 days, but it is often about a month before egg production returns to normal.

Post-mortem examination shows the carcass to be fevered. The crop is often partly impacted with grass and the contents are sour-smelling. The most striking lesion is nephritis, usually accompanied by visceral gout. The ovules are misshapen as a result of absorption and the yolk appears to be thinnish in consistency and sometimes has a greenish tinge. Frequently an ovule ruptures, allowing yolk to escape into the abdominal cavity.

Treatment is empirical. Food is withheld for $12 \mathrm{hr}$. and Epsom salts are given in the mash or in the drinking water. This is said to give satisfactory results in the early stages. Potassium salts have also been tried, with variable results.

In conclusion I should like to stress what should have been obvious from this paper, namely, the importance of an adequate and complete diet for breeding stock, thus ensuring under normal conditions of incubation and brooding the hatching and rearing of healthy, vigorous chicks well equipped to withstand the rigours of post-embryonic life. A deficiency of any essential constituent, whether vitamin or mineral, in the food of the adult may result in poor fertility and give rise to a high embryonic mortality and weakly chicks, handicapped in life from the outset.

\section{REFERENCES}

Greenwood, A. W. \& Blyth, J. S. S. (1948). World's Poult. Congr. virt. Copenhagen, p. 687.

Kull, K.-E. (1948). World's Poult. Congr. virl. Copenhagen, p. 124.

Temperton, H. \& Bythell, D. W. P. (1944). Vet. Rec. 56, 409.

\section{Some Peculiarities of Avian Metabolism}

\section{By W. Bolton, Poultry Research Centre, King's Buildings, West Mains Road, Edinburgh, 9}

In this paper on avian nutrition I propose to deal with peculiarities in nitrogen and calcium metabolism. These can both be traced back to the oviparous mode of reproduction in the fowl and, before they are considered in detail, the radical differences between oviparous and viviparous animals should be discussed.

First of all, the avian embryo develops inside a hard box, the cleidoic egg, whose shell is composed largely of calcium carbonate; the mammalian embryo develops in the uterus. The shell is necessary to provide protection for the developing embryo, but as it is fairly impervious to water it also helps to keep down evaporation losses from the 